\title{
Assessment of Community Pharmacist's Practice and Patient Counselling Toward Acute Diarrhea Treatment in Khartoum Locality: A Simulated Patient Study
}

\author{
Riham M Hamadouk (D) \\ Ahmed H Arbab (D) ${ }^{2}$ \\ Bashir A Yousef $\mathbb{D D}^{3}$ \\ 'Department of Clinical Pharmacy, \\ Faculty of Pharmacy, University of \\ Khartoum, Khartoum, Sudan; \\ ${ }^{2}$ Department of Pharmacognosy, Faculty \\ of Pharmacy, University of Khartoum, \\ Khartoum, Sudan; ${ }^{3}$ Department of \\ Pharmacology, Faculty of Pharmacy, \\ University of Khartoum, Khartoum, \\ Sudan
}

Background: Acute diarrhea is one of the most common health problems globally as a minor ailment, it is widely managed by community pharmacists (CPs). Professional patient counseling provided in community pharmacies is essential to decide about acute diarrhea and avoid treatment failure properly.

Objective: To assess CPs' history-taking practice, medication dispensing, and patient counseling in response to acute diarrhea in adults.

Methods: A cross-sectional, covert simulated patient (SP) study was conducted in 235 community pharmacies in the Khartoum locality. Two scenarios were used, one scenario assesses afterwards compliance to treatment guidelines and patient counseling, and second scenario determines afterwards if pharmacists referred patients to medical consultation. Six final-year pharmacy students were involved as SPs. All encounters were audio-recorded by SP. Then the investigator filled the checklist that was intended to evaluate the overall practice of pharmacists. Results: As planned, 235 pharmacies were visited twice, resulting in a total of 470 visits (visit completion rate: $100 \%$ ). In history taking, the most asked questions were the patient's age $(89.8 \%$ for scenario 1 and $88.5 \%$ for scenario 2$)$. Followed by the presence of blood in the stool $(25.5 \%$ for scenario 1 and $28.1 \%$ for scenario 2$)$. In scenario 1 , loperamide was the most dispensed medication (81.3\%), while oral rehydration solution (ORS) was dispensed in $0.9 \%$ of the visits. In counseling, verbal and written instructions were provided in $47.7 \%$ of the visits. Duration of medications was mentioned in $3.8 \%$, advice about fluid intake was offered in $7.2 \%$ of the visits. In scenario $2,17 \%$ of the pharmacists managed patient history well to refer patients to medical consultation, while $42.6 \%$ recommended referral after sufficient information was provided by the SP.

Conclusion: CPs' practice in counseling toward acute diarrhea was poor; referral to medical consultation was below expectation. The current CPs dispensing practices need improvement; thus, professional education should be encouraged.

Keywords: acute diarrhea, community pharmacists, simulated patient, medical consultation

\section{Introduction}

Community pharmacists have an enormous role in the healthcare delivery system. They are the most accessible health-care members, and they provide valuable information to people who visit the pharmacy, from simple advice about a healthy lifestyle to understanding the correct use of the medications. ${ }^{1}$ According to existing evidence, the 
intervention done by the pharmacist like counseling led to the avoidance of many problems connected to drugs and enhanced the appropriate medicine use. ${ }^{2}$ Worldwide, and as a result of removing many drugs from the list of prescriptiononly medications and inserting them into the list of over-thecounter medications (OTC), the variety of OTC drugs increased. Another factor that also affects the number of medical products that can be dispensed as OTC is the patients' desire to have a greater role in taking care of their health. $^{3}$

Many patients depend on community pharmacists for treating minor ailments like pain, fever, constipation, and acute diarrhea, and for achieving optimum patient care pharmacists must be knowledgeable about treatment guidelines. The pharmacist must be aware of the specific information related to the patient, including demographic data, the medical history of the patient, and the current complaints, and this cannot be obtained unless the pharmacist asked key questions to the patient. ${ }^{4}$

Despite acute diarrhea is considered as one of the most common health problems in the world, ${ }^{5}$ and the Global Burden of Diseases reported that diarrhea was the major cause of death among all ages, about 1.3 million deaths, and 2.3 billion illnesses were due to acute diarrhea in $2015,{ }^{6,7}$ it remains a minor aliment that is managed by community pharmacists. The most common etiology of acute diarrhea in adults is viral infections which are self-limited conditions, while traveling, foodborne illness, and comorbidities that are related to bacterial causes of acute diarrhea. ${ }^{8}$

The basic therapy for diarrhea is rehydration through solutions containing glucose and salt. The World Health Organization (WHO) recommends oral rehydration salts (ORS), ${ }^{9}$ along with loperamide which is considered the firstline choice for controlling diarrhea because it lacks the central nervous system (CNS) effects. ${ }^{10}$ Also, in many countries, loperamide is available as an OTC drug for selfmedication. ${ }^{11}$ In developing countries like Sudan, economic status affects patients' ability to access health services. ${ }^{12}$ The majority of the patients depend on community pharmacies to receive their medical care for minor ailments. In Sudan, community pharmacies are managed by pharmacists. All pharmacists graduate from their faculties with a Bachelor of Pharmacy (B. Pharm.) degree. After graduation, they temporarily registered in the Sudanese Medical Council (SMC) until they finished their public sector internship. After passing the SMC registration examination, they are given a permanent license, which allows them to work in community pharmacies and other pharmaceutical sectors. ${ }^{13}$
Acute diarrhea is a common ailment in Sudan and is being treated through community pharmacies, and because it can be a symptom of several diseases, it is vital to know if pharmacists can manage this condition properly. Since there is insufficient information on the management of acute diarrhea in Sudan, and the sole study investigating pharmacists' practice in managing diarrhea in Sudan was regarding children with diarrhea, ${ }^{14}$ this current study aimed to assess community pharmacists' practice in the Khartoum locality regarding acute diarrhea in adults. Starting from history taking, medication dispensing, quality of advice provided, and referral to medical consultation when it is needed using the simulated patient approach.

\section{Methodology Study Design}

A cross-sectional design was chosen according to the STROBE statement, ${ }^{15}$ to assess community pharmacists' practice on acute diarrhea treatment and patients' counseling concerning Khartoum locality pharmacies using the simulated patient method. Simulated patient (SP) methodology or mystery shopping technique is the method in which test buyers simulated a seemingly real situation to assess the quality of services provided. It is a wellaccepted method that is established internationally to evaluate community pharmacists' professional performance. ${ }^{16}$ The justification of using the simulated patient method is that it minimizes the Hawthorne effect (changing behavior under observation), as the pharmacists may change their performance when they are aware of the presence of a test.

\section{Scenarios}

Two test scenarios were designed both of scenarios to initially evaluate history-taking practice. One scenario assesses afterwards compliance to international treatment guidelines and patient counseling, ${ }^{8}$ while the other scenario determines afterwards if pharmacists referred patients to medical consultation. The details for both scenarios are demonstrated in Table 1.

\section{Sample Size and Sampling}

The total number of community pharmacies in the Khartoum locality represents the study population $\mathrm{N}=568$, it was obtained from a list containing all registered community pharmacies in Khartoum locality that was provided from The Sudanese General Directorate of Pharmacy. The necessary sample size required for this study is $n=235$, according to 
Table I Simulated Patient Scenarios

\begin{tabular}{|l|}
\hline Scenario I \\
\hline The simulated patient enters the pharmacy ask for medication to \\
treat acute diarrhea \\
\hline The following information will be supplied if the pharmacist asked the \\
simulated patient: \\
- He is 30 years old \\
- Complains from diarrhea for one day \\
- Diarrhea is several times per day \\
- There are abdominal cramps and no other symptoms \\
- No medication used recently \\
\hline Scenario 2 \\
\hline The simulated patient enters the pharmacy ask for medication to \\
treat acute diarrhea \\
\hline The following information will be supplied if the pharmacist asked the \\
simulated patient \\
- The patient is 73 years old woman \\
- Diarrhea started 4 days ago \\
- Diarrhea is several times per day \\
- The Patient with high fever, and there is blood in the stool \\
- The patient is diabetic \\
\hline
\end{tabular}

the equation: $\mathrm{n}=\mathrm{N} / 1+\mathrm{N}(\mathrm{e})^{2}$, where (e) an error margin of 0.05 , the formula is based on a degree of variability of $\mathrm{P}=0.5$, and a $95 \%$ confidence interval. ${ }^{17}$

A total of 235 community pharmacies were randomly selected and visited twice by different scenarios. The visits were audio-recorded to enhance data integrity, as audio recording minimizes inaccuracies resulting from the simulated patients' poor recall abilities, which are considered a potential shortcoming of the simulated patient technique. ${ }^{18}$

\section{Assessment Form}

The assessment form was a checklist developed in accordance with the World Health Organization (WHO) manual for diarrhea treatment and from the American College of Gastroenterology Clinical Guidelines. ${ }^{19,20}$ It consisted of two parts; the first part (for both scenarios) was about the required questions that must be asked when taking a complete patient's history. These questions will allow the pharmacist to decide to dispense medication or refer the patient to medical consultation. The questions in this part include asking about the patient's age, the duration of diarrhea, and eight other questions (Table 2). The second part of the checklist was different for each scenario. In scenario one, the name of the dispensed medication and some of the counseling items related to the proper use of the medications were included, such as information about the right dose, route of administration, and frequency (Table 2). For scenario two, the second part of the checklist assesses whether the pharmacist referred the patient to medical consultation before and after SP provides information indicates referral (Table 2).

\section{Data Collection}

Six final-year B. Pharm. students from the Faculty of Pharmacy, University of Khartoum, were selected as simulated patients (SPs), two males and four females. They were trained to act as patients, to introduce and develop the two scenarios. After they had been familiar with their scenario, a pilot study was made by the SPs in Khartoum locality to ensure their ability to perform the scenarios given and test the validity of the checklist. Eighteen community pharmacies were visited during the pilot study (three visits for each SP), and they were excluded from this study. The six SPs were randomized into two groups from three members, each group responsible for one scenario. For each scenario, randomization was made to assign community pharmacies across the three SPs to complete a total of 235 visits. In the visits, the SPs requested a pharmacist first before starting the portrayal to ensure that the study assessing only pharmacists. Additional information was supplied by the SPs only upon pharmacists' request. In scenario 2 if referral was not recommended, then the information that indicates referral (diabetic patient, high fever, blood in the stool) was provided to see the pharmacist's response. Immediately after each pharmacy visit and to minimize data omissions, the investigator filled the checklist that was intended to evaluate the overall practice of pharmacists from SPs and the audio records.

\section{Data Management and Analysis}

For analysis of data, Statistical Package for Social Sciences software, version 23.0 (IBM SPSS Inc., Chicago, IL) was used. Initially, all information were gathered via recording notes, which are then coded into variables. Descriptive statistics were used to present the results, and data were illustrated as tables that contain numbers and frequencies for pharmacists with correct practice.

\section{Ethical Consideration}

The study was approved by the Ethical Committee of the Faculty of Pharmacy, University of Khartoum (FPEC-032020). Additional approval was obtained from the scientific research authority ministry of health. In October 2020, written informed consent was collected from all the 
Table 2 Assessment Items on the Checklist for Scenario I and Scenario 2

\begin{tabular}{|c|c|c|}
\hline \multicolumn{3}{|l|}{ Part I (for Scenario I and 2) } \\
\hline \multirow[t]{2}{*}{ Variables } & \multicolumn{2}{|c|}{ Coding } \\
\hline & Discussed & Not Discussed \\
\hline I. How old is the patient? & I & 0 \\
\hline 2. How long has the diarrhea been present? & 1 & 0 \\
\hline 3. How often the diarrhea occurred? & I & 0 \\
\hline 4. Is vomiting accompanied diarrhea? & 1 & 0 \\
\hline 5. Is fever accompanied diarrhea? & 1 & 0 \\
\hline 6. Is blood presented in the stool? & I & 0 \\
\hline 7. Does this condition has occurred before? & I & 0 \\
\hline 8. Has the patient travelled recently? & I & 0 \\
\hline 9. Are they any family member affected? & I & 0 \\
\hline 10. Are they any medications used by the patient? & I & 0 \\
\hline \multicolumn{3}{|l|}{ Part 2 (for Scenario I) } \\
\hline \multicolumn{3}{|l|}{ Name of the medication dispensed } \\
\hline \multirow{4}{*}{$\begin{array}{l}\text { Verbal and written instructions about dose, frequency, and route of } \\
\text { administration } \\
\text { Verbal instructions about dose, frequency, and route of administration }\end{array}$} & Correct & Wrong \\
\hline & 1 & 0 \\
\hline & 1 & 0 \\
\hline & Discussed & Not Discussed \\
\hline Information about duration of the medication & 1 & 0 \\
\hline Provision of advice to patient & 1 & 0 \\
\hline \multicolumn{3}{|l|}{ Type of the advice } \\
\hline \multicolumn{3}{|l|}{ Part 2 (for Scenario 2) } \\
\hline \multicolumn{3}{|l|}{ Response of pharmacists toward the scenario } \\
\hline Before scenario told & Before scenario told & Coding \\
\hline Recommend referral & Recommend referral & 1 \\
\hline Dispense medication & Dispense medication & 0 \\
\hline
\end{tabular}

community pharmacists who participated in the study. It informed the pharmacists that the study might include audio recording, and these records would be deleted directly after collecting the necessary data for the research. The pharmacists did not know the time of the visit or even the name of the research, they knew that it would assess their practice, and they all agreed to participate. Moreover, to protect the effectiveness of the covert study design, the data was collected between December 2020 and February 2021. Another participation agreement was collected after the completion of the data collection. All collected checklists were coded while ensuring confidentiality throughout the study.

\section{Results}

As planned, 235 pharmacies were visited twice, resulting in a total of 470 visits (visit completion rate: 100\%). In history taking, the most asked questions were the patient age (89.8\% for scenario 1 and $88.5 \%$ for scenarios 2 ). Followed by the presence of blood in the stool $(25.5 \%$ for scenario 1 and $28.1 \%$ for scenario 2 ), and duration of acute diarrhea $(24.7 \%$ for scenario 1 and $22.1 \%$ for scenario 2). While, recent traveling abroad was not asked by any pharmacist in either scenario. The rest of the results are listed in Table 3.

With regard to medication dispensed in scenario 1 five drugs were dispensed either alone or in combination. The 
Table 3 Diarrhea History-Taking Practice of the Community Pharmacists for Scenario I $(n=235)$ and Scenario $2(n=235)$

\begin{tabular}{|l|l|l|}
\hline \multirow{2}{*}{ History Taking Practice Items } & \multicolumn{2}{|c|}{ Number of Pharmacists (\%) } \\
\cline { 2 - 3 } & Scenario I & Scenario 2 \\
\hline Age & $211(89.8)$ & $208(88.5)$ \\
Duration & $58(24.7)$ & $52(22.1)$ \\
Severity & $57(24.3)$ & $49(20.9)$ \\
Vomiting & $23(9.8)$ & $25(10.6)$ \\
Fever & $26(11.1)$ & $29(12.3)$ \\
Blood in the stool & $60(25.5)$ & $66(28.1)$ \\
Previous history & $45(19.1)$ & $47(20)$ \\
Recent travel abroad & $0(0)$ & $0(0)$ \\
Other family members affected & $0(0)$ & $1(0.4)$ \\
Medication used by the patient & $12(5.1)$ & $29(12.3)$ \\
\hline
\end{tabular}

most dispensed medication (81.3\%) was loperamide followed by metronidazole (11.5\%), while the combination loperamide + co-trimoxazole was the least dispensed medication $(0.4 \%)$ (Table 4 for more details).

In terms of dispensing practice, information regarding the proper use of medications specifically, dose, frequency, and route of administration, verbal and written instructions were provided in $47.7 \%$ of the visits. Wrong instructions about dose and frequency provided in $16.6 \%$ visits. Advice about fluid intake was offered in $7.2 \%$ of the visits, and information about the duration of medication was provided in $3.8 \%$ visits. Additional results are presented in Table 5 .

In scenario $2,17 \%$ of the pharmacists managed patient history well to refer patients to medical consultation, $42.6 \%$ pharmacists dispensed a medication then recommended referral to medical consultation after sufficient information was provided by the SP, while in more than $40 \%$ of the visits a medicine was dispensed instead of recommending medical consultation. Responses of pharmacists are summarized in Table 6.

Table 4 The Medications Dispensed During the Simulated Patient Study of Scenario I $(n=235)$

\begin{tabular}{|l|l|}
\hline Name of Dispensed Medication & Number (Frequency \%) \\
\hline Loperamide & $191(81.3)$ \\
Metronidazole & $27(11.5)$ \\
Loperamide + Metronidazole & II (4.7) \\
Oral Rehydration Solution (ORS) & $2(0.9)$ \\
Loperamide + Doxycycline & $2(0.9)$ \\
Metronidazole + Doxycycline & $\mathrm{I}(0.4)$ \\
Loperamide + Co-trimoxazole & $\mathrm{I}(0.4)$ \\
\hline
\end{tabular}

Table 5 The Number of Pharmacists in Scenario I Who Offered Instruction on How to Use the Medication Which Includes Dose, Route of Administration and Frequency to the Simulated Patient, and Other Counseling Content

\begin{tabular}{|l|l|}
\hline $\begin{array}{l}\text { Instruction on How to Use the } \\
\text { Medication }\end{array}$ & $\begin{array}{l}\text { Number of } \\
\text { Pharmacists (\%) }\end{array}$ \\
\hline Pharmacists said and write instructions & $\mathrm{II}(47.7)$ \\
\hline Pharmacists said only & $75(31.9)$ \\
\hline $\begin{array}{l}\text { Pharmacists provided wrong } \\
\text { instructions }\end{array}$ & $39(16.6)$ \\
\hline $\begin{array}{l}\text { Pharmacists did not give any } \\
\text { instructions }\end{array}$ & $9(3.8)$ \\
\hline Duration of the medication & $9(3.8)$ \\
\hline Advice that is given to the patient & $17(7.2)$ \\
\hline
\end{tabular}

Table 6 The Action Made by Community Pharmacists Toward Scenario $2(n=235)$

\begin{tabular}{|l|l|}
\hline $\begin{array}{l}\text { Response of Community Pharmacists } \\
\text { Toward Scenario 2 }\end{array}$ & $\begin{array}{l}\text { Number of } \\
\text { Pharmacists (\%) }\end{array}$ \\
\hline Referred patient to medical consultation & $40(17)$ \\
\hline $\begin{array}{l}\text { Give medication then referred after scenario } \\
\text { told }\end{array}$ & $100(42.6)$ \\
\hline $\begin{array}{l}\text { Give medication then not referred after } \\
\text { scenario told }\end{array}$ & $95(40.4)$ \\
\hline
\end{tabular}

\section{Discussion}

Community pharmacists play a crucial role in treating minor ailments and providing proper advice to patients, especially in developing countries where the resources are limited and patients prefer free fees medical consultation, ${ }^{21}$ as patients can obtain medicines from community pharmacies without visiting a doctor. And as acute diarrhea is one of the common minor ailments, this study assesses community pharmacists' practice toward acute diarrhea treatment and patient counseling in adults. Overall results of this study show poor pharmacy practice in terms of history taking, dispensing, counseling, and referral to medical consultation.

To treat acute diarrhea, the pharmacist must distinguish between different types of diarrhea, and this is done only by taking a complete patient history. ${ }^{20}$ Asking questions about onset, duration, severity, and frequency of diarrhea, along with the presence of any other symptoms like fever and vomiting are important. Also, the type of stool if it is 
bloody or watery, if the patient has any other diseases, or if he or she has recently taken any medications needed to be investigated. $^{22}$

It depends on the duration of symptoms diarrhea is classified as acute, persistent, and chronic, and when diarrhea lasts more than 14 days many probabilities will be considered as the etiology. ${ }^{9}$ This study shows that less than a quarter of the pharmacists in this study asked about the duration of acute diarrhea, which was less frequent compared to international studies. In a study in Germany, this question was asked by $48.7 \%$ pharmacists. ${ }^{5}$ A higher result was observed in a study done in Iraq where almost $80 \%$ of pharmacists asked about the duration. ${ }^{22}$ Moreover, in a study in Trinidad, 98.9\% pharmacists thought it important to ask patients about the duration of the diarrhea. $^{23}$ The results related to this question were even worse than what founded by the Turkish SP study done in 2015, which studied the attitude of community pharmacists and pharmacy technicians towards acute diarrhea in adults where it was asked by $26 \%$ of pharmacists. ${ }^{4}$

History of medications used by the patient considered one of the important questions that must be asked; to rule out a predictable reason for diarrhea as many drugs can cause diarrhea, ${ }^{24}$ in this study, only $12(5.1 \%)$ pharmacists in scenario 1 , and $29(12.3 \%)$ pharmacists in scenario 2 asked about medication history, in the Turkish study this question was not asked at all. ${ }^{4}$ On the other hand, in a study conducted in Germany, ${ }^{5}$ this question was asked in $32.7 \%$ of the simulated patient visits.

Many symptoms that accompany acute diarrhea can help in linking it to its cause. Even though vomiting is common in cholera and is an indicator of the presence of a bacterial toxin, as well as fever which also predicts the involvement of different pathogens, ${ }^{25}$ the majority of pharmacists did not ask questions about these concomitant symptoms. Also, questions about the severity, which is a clue of the degree of dehydration, ${ }^{25}$ and previous history of diarrhea, which can be a sign of diseases like irritable bowel syndrome or Crohn's disease, and both required referral, were neglected by most of the pharmacists. ${ }^{26}$

Traveler's diarrhea is diarrhea that happens to tourists when they visit developing countries, it has an incidence rate of $10 \%$ to $40 \%{ }^{27}$ Many pathogens can cause it, but bacteria are the predominant causative agent, and Africa is considered as a high-risk region for traveler's diarrhea. ${ }^{28}$ In this study, the question of recent traveling was not asked by any pharmacist in both scenarios. The findings revealed poor history-taking by community pharmacists compared to the Iraqi study, which found that the historytaking practice to some extend satisfactory. ${ }^{22}$

Oral rehydration salts (ORS) is the first-choice treatment for acute diarrhea along with loperamide in adults according to the standard treatment guidelines suggested by World Gastroenterology Organization. ${ }^{25}$ Only $2(0.9 \%)$ pharmacists dispensed ORS in this study, this low rate of ORS dispensing was also seen in comparable studies almost about $1 \%$ from Iraq, ${ }^{22}$ and about $4 \%$ from Qatar. $^{29}$ While in studies from Turkey and Germany this preparation was not dispensed. ${ }^{4,11}$ In contrast, in a selfassessment study conducted in Trinidad, 64\% pharmacists recommended ORS, including 51\% pharmacists who followed the recommended WHO guidelines. ${ }^{23}$ Our findings noted that loperamide was highly recommended by 191 $(81.3 \%)$ pharmacists, similar to what was observed in the findings of the symptom-based scenario from a German study in which preparations containing loperamide were dispensed by $76 \%$ of the pharmacists. ${ }^{11}$ Additionally, in Qatar's SP study, loperamide was also the highly dispensed medication $(37.9 \%){ }^{29}$ Ironically, loperamide was dispensed only by $16 \%$ of the pharmacists in a study conducted in Pakistan. ${ }^{6}$

In accordance with a study conducted in Iraq, antibiotics (alone or in combination) were not widely preferred by pharmacists. ${ }^{22}$ Antibiotics were dispensed in less than $20 \%$ of the cases. In contrast, in the study from Pakistan, metronidazole alone was recommended in $78.1 \%$ of the cases. ${ }^{6}$ Despite the fairly low proportion of antibiotics used in the current study, still it is inappropriate.

According to Riddle et al, most cases of acute diarrhea are from viral etiology, and antibiotics will not shorten the duration of diarrhea. ${ }^{20}$ Thus, the use of them should be discouraged. In the part of how the medication used which include dose, frequency, route of administration, and duration, $47.7 \%$ of pharmacists emphasized these instructions verbally and written, $31.9 \%$ mentioned them verbally only and $3.8 \%$ did not give any instruction, while $16.6 \%$ pharmacist gave wrong instructions. Only $4 \%$ provided information about the duration and $7 \%$ advised the patient which was all on increased fluid intake. The results regarding counseling and quality of advice were poor, similar to the findings observed in studies from Germany, Iraq, and Qatar, $^{3,22,29}$ which all concluded poor quality of counseling. Furthermore, in a Saudi Arabia study that assessed pharmacists' counseling practice in the Qassim region, the counseling practice was poor. ${ }^{1}$ 
In addition to dispensing medication and counseling, advising the patient on visiting a doctor when it is necessary is considered one of the important pieces of information that should be provided to the patients. In this present study, scenario 2 represents a case that necessitates referral. Only $40(17 \%)$ of the pharmacists referred the patients to medical consultation, and 100 (42.6\%) pharmacists dispensed a medication first and then recommended referral to medical consultation after sufficient information was provided by the simulated patients, which was not requested by the pharmacist in history taking. Unexpectedly 95 (40.4\%) pharmacists insisted not to refer the patients and gave medication despite their knowledge of all information. The results in this scenario were below expectation, unlike the German study which assesses if pharmacy staff refer patients to medical consultation when indicated, almost $60 \%$ of pharmacy staff recommended visiting a doctor. ${ }^{5}$ In the Australian SP study about ailments requiring referral in the pharmacy, a high rate compared to this study was also observed; the referral rate was $57 \%$ for acute diarrhea. ${ }^{30}$

This study has some limitations. One of them is a crosssectional study done only in the Khartoum locality; thus, the results cannot be generalized to all community pharmacists working in the entire country. Another shortcoming was the absence of pharmacist's demographic data, which was difficult to collect at the time of the visits, not to jeopardize the covert of the simulated patient methodology. And, due to the high number of community pharmacies and limited time and resources, it was not collected after the visits. Also, the current study did not clarify if the gender of pharmacists can affect the quality of healthcare provided to patients.

\section{Conclusion}

It was observed that community pharmacists dispensing practice in response to acute diarrhea in adults was poor. Insufficient questioning in history-taking practice was identified, the most commonly asked question was the patient's age. Most pharmacists recommended loperamide as a first-line treatment option, while oral rehydration was dispensed only twice. Inappropriate dispensing of antibiotics was observed. The quality of counseling was poor, less than half of pharmacists provided basic information on how to use the medication. Therefore, a substantial improvement of pharmacists' attitude towards acute diarrhea in adults is needed. Enhancing community pharmacists to continuing professional education should be encouraged through relevant education and training programs to achieve optimal pharmacists practicing and proper healthcare provision at the community pharmacies.

\section{Acknowledgments}

The authors acknowledge all participants acted as simulated patients.

\section{Funding}

There is no funding to report.

\section{Disclosure}

The authors declare no conflicts of interest for this work.

\section{References}

1. Alfadl AA, Alrasheedy AA, Alhassun MS. Evaluation of medication counseling practice at community pharmacies in Qassim region, Saudi Arabia. Saudi Pharm J. 2018;26(2):258-262. doi:10.1016/j. jsps.2017.12.002

2. Alaqeel S, Abanmy NO. Counselling practices in community pharmacies in Riyadh, Saudi Arabia: a cross-sectional study. BMC Health Serv Res. 2015;15(1):557-566. doi:10.1186/s12913-015-1220-6

3. Langer B, Bull E, Burgsthaler T, Glawe J, Schwobeda M, Simon K. Assessment of counselling for acute diarrhoea in German pharmacies: a simulated patient study. Int J Pharm Pract. 2018;26 (4):310-317. doi:10.1111/ijpp.12405

4. Sancar M, Tezcan E, Okuyan B, Izzettin FV. Assessment of the attitude of community pharmacists and pharmacy technicians towards diarrhea: a simulated patient study in Turkey. Trop J Pharm Res. 2015;14(8):1509-1515. doi:10.4314/tjpr.v14i8.26

5. Langer B, Kunow C. Do north-eastern German pharmacies recommend a necessary medical consultation for acute diarrhoea? Magnitude and determinants using a simulated patient approach. F1000Res. 2019;8(1841):1-24. doi:10.12688/f1000research.21045.1

6. Khan A, Iqbal Q, Haider S, Khalid A, Hassali MA, Saleem F. Acute diarrheal management in adults: a simulated client study at community pharmacies of Quetta City, Pakistan. J Pharm Pract Community Med. 2019;5(1):13-17. doi:10.5530/jppcm.2019.1.3

7. Troeger C, Forouzanfar M, Rao PC, et al. Estimates of global, regional, and national morbidity, mortality, and aetiologies of diarrhoeal diseases: a systematic analysis for the Global Burden of Disease Study 2015. Lancet Infect Dis. 2017;17(9):909-948. doi:10.1016/S1473-3099(17)30276-1

8. Doe WF, Barr GD. Acute diarrhoea in adults. Aust Fam Physician. 1981;10(6):438-446.

9. Lübbert C. Antimicrobial therapy of acute diarrhoea: a clinical review. Expert Rev Anti Infect Ther. 2016;14(2):193-206. doi:10.1586/14787210.2016.1128824

10. Regnard C, Twycross R, Mihalyo M, Wilcock A. Loperamide. J Pain Symptom Manage. 2011;42(2):319-323. doi:10.1016/j. jpainsymman.2011.06.001

11. Langer B, Kunow C. Medication dispensing, additional therapeutic recommendations, and pricing practices for acute diarrhoea by community pharmacies in Germany: a simulated patient study. Pharm Pract (Granada). 2019;17(3):1579-1588. doi:10.18549/ PharmPract.2019.3.1579

12. Awad AI, Eltayeb IB, Capps PA. Self-medication practices in Khartoum State, Sudan. Eur J Clin Pharmacol. 2006;62 (4):317-324. doi:10.1007/s00228-006-0107-1 
13. Alfadl AA, Ali GKM, Yousif MA, Ahmed Babekir MF. Chapter 16 Pharmacy practice in Sudan. In: Fathelrahman AI, Ibrahim MIM, Wertheimer AI, editors. Pharmacy Practice in Developing Countries. Boston: Academic Press; 2016:319-341.

14. Berih AA, McIntyre L, Lynk AD. Pharmacy dispensing practices for Sudanese children with diarrhoea. Public Health. 1989;103 (6):455-458. doi:10.1016/S0033-3506(89)80056-3

15. von Elm E, Altman DG, Egger M, Pocock SJ, Gøtzsche PC, Vandenbroucke JP. The Strengthening the Reporting of Observational Studies in Epidemiology (STROBE) statement: guidelines for reporting observational studies. PLoS Med. 2007;4 (10):0040296. doi:10.1371/journal.pmed.0040296

16. Björnsdottir I, Granas AG, Bradley A, Norris P. A systematic review of the use of simulated patient methodology in pharmacy practice research from 2006 to 2016. Int J Pharm Pract. 2020;28(1):13-25. doi:10.1111/ijpp. 12570

17. Kasiulevičius V, Šapoka V, Filipavičiūtė R. Sample size calculation in epidemiological studies. Gerontologija. 2006;7(4):225-231.

18. Werner JB, Benrimoj SI. Audio taping simulated patient encounters in community pharmacy to enhance the reliability of assessments. $\mathrm{Am}$ J Pharm Educ. 2008;72(6):136. doi:10.5688/aj7206136

19. Organization WH. The Treatment of Diarrhoea: A Manual for Physicians and Other Senior Health Workers. 4th rev ed. World Health Organization; 2005. Available from: https://apps.who.int/iris/ handle/10665/43209. Accessed November 11, 2021.

20. Riddle MS, DuPont HL, Connor BA. ACG clinical guideline: diagnosis, treatment, and prevention of acute diarrheal infections in adults. Am J Gastroenterol. 2016;111(5):602-622. doi:10.1038/ ajg.2016.126

21. Oyetunde O, Williams V. Community pharmacists' views of the use of oral rehydration salt in Nigeria. Int J Clin Pharm. 2018;40 (3):659-667. doi:10.1007/s11096-018-0616-x
22. Ibrahim IR, Palaian S, Ibrahim MI. Assessment of diarrhea treatment and counseling in community pharmacies in Baghdad, Iraq: a simulated patient study. Pharm Pract (Granada). 2018;16 (4):1313-1319. doi:10.18549/PharmPract.2018.04.1313

23. Karim R, Ramdahin P, Boodoo JR, Kochhar A, Pinto Pereira LM. Community pharmacists' knowledge and dispensing recommendations for treatment of acute diarrhoea in Trinidad, West Indies. Int $J$ Clin Pract. 2004;58(3):264-267. doi:10.1111/j.13685031.2004.0095.x

24. Abraham BP, Sellin JH. Drug-induced, factitious, \& idiopathic diarrhoea. Best Pract Res Clin Gastroenterol. 2012;26(5):633-648. doi:10.1016/j.bpg.2012.11.007

25. Farthing M, Salam MA, Lindberg G, et al. Acute diarrhea in adults and children: a global perspective. J Clin Gastroenterol. 2013;47 (1):12-20. doi:10.1097/MCG.0b013e31826df662

26. Blenkinsopp A, Paxton P, Blenkinsopp J. Symptoms in the Pharmacy. Wiley Online Library; 2007.

27. Steffen R, Hill DR, DuPont HL. Traveler's diarrhea: a clinical review. JAMA. 2015;313(1):71-80. doi:10.1001/jama.2014.17006

28. Mattila L. Clinical features and duration of traveler's diarrhea in relation to its etiology. Clin Infect Dis. 1994;19(4):728-734. doi:10.1093/clinids/19.4.728

29. Ibrahim MI, Palaian S, Al-Sulaiti F, El-Shami S. Evaluating community pharmacy practice in Qatar using simulated patient method: acute gastroenteritis management. Pharm Pract (Granada). 2016;14 (4):800-808. doi:10.18549/PharmPract.2016.04.800

30. Collins JC, Schneider CR, Faraj R, Wilson F, de Almeida Neto AC, Moles RJ. Management of common ailments requiring referral in the pharmacy: a mystery shopping intervention study. Int J Clin Pharm. 2017;39(4):697-703. doi:10.1007/s11096-017-0505-8
Integrated Pharmacy Research and Practice

\section{Publish your work in this journal}

Integrated Pharmacy Research and Practice is an international, peerreviewed, open access, online journal, publishing original research, reports, reviews and commentaries on all areas of academic and professional pharmacy practice. This journal aims to represent the academic output of pharmacists and pharmacy practice with particular focus on integrated care. All papers are carefully peer reviewed

\section{Dovepress}

to ensure the highest standards as well as ensuring that we are informing and stimulating pharmaceutical professionals. The manuscript management system is completely online and includes a very quick and fair peer-review system, which is all easy to use. Visit http://www.dovepress.com/testimonials.php to read real quotes from published authors. 